\title{
Melatonin hormone stimulates human clock genes on neuroblastoma (SH-SY5Y) cell line
}

\author{
Şefik Güran 1, Vildan Tunçbilek ${ }^{2}$, Meral Zehra Baykara ${ }^{2}$, Zehra Dilşad Çoban ${ }^{3}$, Yunus Emre Polat ${ }^{2}$, \\ Yiğit Cemo Kılıç ${ }^{2}$, Zehra Zeynep Kaplan ${ }^{2}$, Özgür Kılıçarslan ${ }^{1}$ \\ (1) University of Health Sciences, Gulhane Medical School, Department of Medical Biology, Ankara, Turkey \\ (2) University of Health Sciences, Gulhane Medical School, Ankara, Turkey \\ (3) National Defense Ministry, Çankaya Pavilion Infirmary, Ankara, Turkey
}

Date submitted:

Jun 02, 2019

Date accepted:

Sep 09, 2019

Online publication date:

December 15, 2019

\section{Corresponding Author: \\ Şefik Güran \\ University of Health Sciences, \\ Gulhane Medical School, \\ Department of Medical Biology, \\ Ankara, Turkey \\ sefik.guran@sbu.edu.tr}

Keywords: Melatonin, circadian rhythm, clock gene, Bmal1 gene, cell viability.

\begin{abstract}
Aims:Circadian rhythm of human body is regulated by melatonin which affects through to hypothalamic area of brain. Human clock genes (Clock, Bmal1, etc.) also actively participate in the circadian rhythm. Cell viability techniques reflect the number of living cells in a population. In this manuscript, human neuroblastoma cell viability was found in melatonin usage. The clock gene expression differences on the same panel were analyzed.

Methods:In cell viability studies, MTT and trypan blue assays were used with melatonin solutions (in $0.25 \mathrm{mM}, 0.50 \mathrm{mM}, 1 \mathrm{mM}$ concentrations) on neuroblastoma cells. In the expressions studies, Clock, Bmal1, Per and Cry genes were studied for gene expressions by using melatonin on RT-PCR.

Results:The melatonin' LD50 was found as $1.2 \mathrm{mM}$ on human neuroblastoma cells. We found that, $81 \pm 1.2 \%, 80 \pm 0.9 \%, 73 \pm 1.2 \%, 73 \pm 1.1 \%$ cells were viable in control, $0.25 \mathrm{mM}, 0.50 \mathrm{mM}, 1 \mathrm{mM}$ melatonin concentrations respectively. In high melatonin concentrations $(0.5 \mathrm{mM}$ and $1 \mathrm{mM})$, Clock and Bmal1 expressions were found higher than control $(p<0.05)$. In low melatonin concentration $(0.25 \mathrm{mM})$, no difference in expression was found on Clock and Bmal 1 genes $(p \geq 0.05)$. No difference in expressions was found in Per and Cry genes by using melatonin $(p \geq 0.05)$.

Conclusions:Melatonin in high concentrations decreased neuroblastoma cell viability. In the same concentrations, melatonin increased the Clock and Bmal1 genes' expressions. Melatonin in low concentration did not chanced cell viability. In the same concentration, no effect on Clock and Bmal1 genes' expressions were observed. We observed no relationship between Per and Cry genes' expressions and melatonin usage.
\end{abstract}

\section{Introduction}

Melatonin is a neurohormone secreted by the pineal gland during dark period of the night. It regulates circadian rhythms including sleep patterns. Melatonin hormone participates on human circadian rhythm. The duration of elevated nocturnal melatonin levels is commensurate to the length of darkness $(1,2)$. Melatonin is a beneficial supplement in the treatment of central nervous system disorders. Melatonin as a potent antioxidant, regulates a large number of molecular pathways, including oxidative stress, inflammation, apoptosis, and cell death (3). The circadian clock system controls daily rhythms in physiology, metabolism, and behavior in mammals. Circadian rhythms are affected by endogenous factors for example Clock genes (including Clock, Bmal1, Per and Cry). The products of these genes stimulate the suprachiasmatic nucleus of the anterior hypothalamus in human brain (4). Clock protein encoded from Clock gene acts as a transcriptional factor. It activates other clock genes. It promotes chromatin opening and regulates DNA accessibility of other transcription factors (5).

Cell viability is one of the basic methods to figure out the viability of cells in culture. The results can be used in evaluation of the effects of substances on relevant cells. There are a number of methods for the detection of cell viability such as fluorescence- or non-fluorescence based methods. Many of these methods require expensive commercial kits, fluorescence dyes/ antibodies etc. Trypan blue assay in cell viability is the cheapest and easiest one (6). Gene expression is a term, used for a genes' activation in the synthesis of a functional gene product. Reverse transcription polymerase chain reaction (RT-PCR) is a laboratory technique which is used for gene expression analy$\operatorname{ses}(7,8)$.

In this study, we aimed to look for the cell viability changes on neuroblastoma cell line in different melatonin concentration by using trypan blue assay. Also we analyzed the expression differences of Clock genes on real time polymerase chain reaction (RT-PCR). The cell viability ratios were found as lower than control in high concentrations' melatonin applications. In low melatonin concentrations, no differences in cell viability was observed. In high concentration melatonin uses, melatonin increased Clock and Bmal1 gene expressions. 


\section{Methods}

This study is designed due to Ethical Board Decision of Gülhane Military Medical Academy-2014-44.

\section{Preparation of Melatonin Solutions}

Melatonin was delivered from Sigma Aldrich Co. (M5250 powder form). Physiological saline solution was used for dilution of melatonin. The melatonin solutions were prepared in different concentrations $(0.25 \mathrm{mM}, 0.50 \mathrm{mM}, 1.0 \mathrm{mM}, 1.25 \mathrm{mM}$, $1.50 \mathrm{mM}, 1.75 \mathrm{mM}, 2.0 \mathrm{mM})$.

\section{MTT Cell Proliferation Assay}

For cell viability and cell proliferation, MTT (3-[4,5-dimethylthiazol-2-yl]-2,5- diphenyltetrazolium bromide; thiazolyl blue) assay was applied in the different concentration of Melatonin after the 24-hour incubation (Sigma-Aldrich/In Vitro Toxicology Assay Kit, MTT based). According to the instruction manual, we noticed to do analyses with $3 \times 104$ cells in each cell culture flask. Melatonin solutions $(50 \mu \mathrm{l}$ in each) were added in neuroblastoma culture flasks. The MTT cell proliferation experiments were done three times for obtain proper results. In cultured cells, Lethal Dose 50 (LD50) was found with Melatonin application (9) (Figure 1).

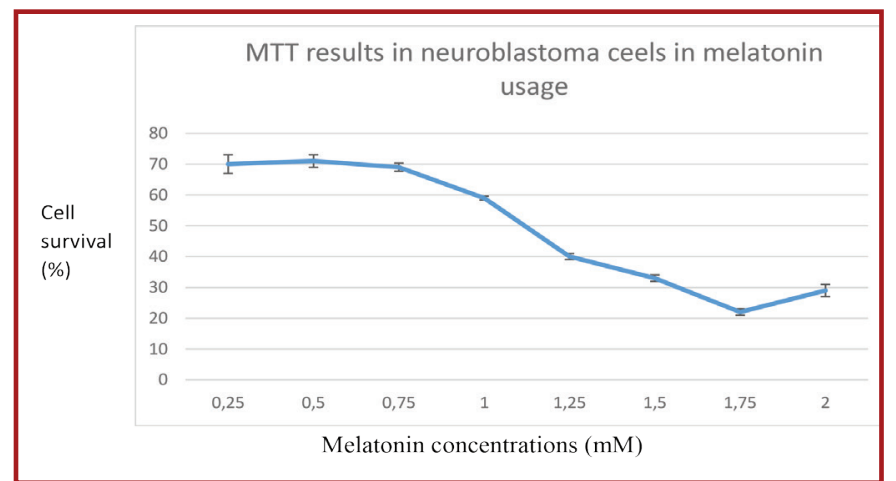

Figure 1. The graph represents MTT results in neuroblastoma cells [SH-SY5Y-ATCC $\otimes ~ C R L-2266^{\mathrm{TM}}$ ] after melatonin treatment (LD50 was found as $1.2 \mathrm{mM}$ ).

\section{Neuroblastoma Cell Culture}

In our study, human neuroblastoma cell line [SH-SY5YATCC $®$ CRL-2266 ${ }^{\mathrm{TM}}$ ] was obtained from Health Sciences University, Gülhane Health Science Institute, Cancer Research Center. The SH-SY5Y neuroblastoma cell line is a well-characterized neuronal cell line with different functional qualities. Naturally, these cells have dopaminergic and adrenergic properties (10). Cell cultures of cell line was applied due to classical standards (11). The cell line was incubated in RPMI-8226 1640 (Sigma-Aldrich-R8758) including $10 \%$ (v/v) FBS (BiochromAG, Germany) and $1 \%(\mathrm{v} / \mathrm{v})$ penicillin and streptomycin (Biological Industries, Israel) $\left(37^{\circ} \mathrm{C}, 5 \% \mathrm{CO} 2\right)$ (Heraus incubator, Henau, Germany) (9). In working conditions, $0.25 \mathrm{mM}, 0.50 \mathrm{mM}$ and $1.0 \mathrm{mM}$ melatonin solutions were chosen. We arranged five cell culture groups; one for control, three for melatonin treatment groups ( $0.25 \mathrm{mM}, 0.5 \mathrm{mM}$ and $1.0 \mathrm{mM}$ melatonin solutions). In control group, only RPMI-1640 (Sigma R8758) as a cell culture medium was used. For study groups, $2 \mathrm{ml}$ of melatonin solution in each was used for one culture flask. The cells were examined immediately after the applications and 24 hour later. The changes in cell morphology were noted. The cells were photographed for morphological analyses.

\section{Cell viability assay with trypan blue}

Trypan blue (Sigma Aldrich Co. 302643) as a stain was used in procedure for viable cell counting. Trypan blue was diluted at $0.8 \mathrm{mM}$ in PBS. It was mixed with the cells $1: 1$. In this method, live (viable) and dead (non-viable) cells were counted on hemocytometer (12). Trypan blue cell viability assay was applied in the different concentration of Melatonin (in $0.25 \mathrm{mM}, 0.50 \mathrm{mM}$, $1.0 \mathrm{mM}$ ) after the 24-hour incubation. The cell viability experiments were done three times for obtain proper results (Figure 2).

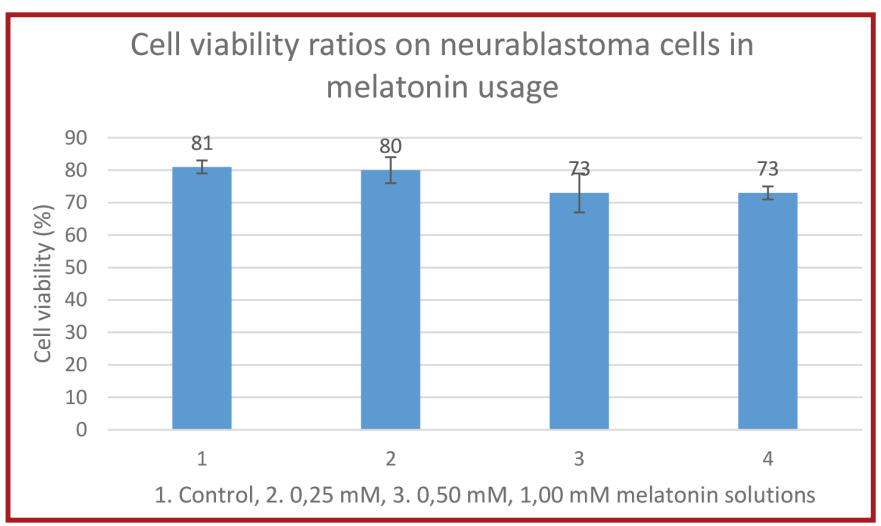

Figure 2. The graph represents cell viability ratios (in \%) in different melatonin solutions on neuroblastoma cells.

\section{RNA isolation and cDNA synthesis}

All of the culture flasks were harvested by Trypsin-EDTA solution (Sigma Aldrich Cat No: T4049) 24 hours later. RNA isolation procedure was performed on the harvested cells according to manufacturer's protocol (NucleoSpin RNA-Machenery Nagel). For cDNA synthesis, RT- PCR was used as $42^{\circ}$ for 60 minutes; $70^{\circ}$ for 5 minutes according to the manufacturer' $s$ protocol (Fermentas, Revert Aid cDNA synthesis kit). c-DNA's were controlled on $2 \%$ agarose gel.

\section{Reverse transcription-polymerase chain reaction-RT PCR}

The gene expression levels of Clock/ Clock Circadian Regulator (OMIM: 601851), Bmal1/ARNTL/Aryl Hydrocarbon Receptor Nuclear Translocator Like (OMIM: 602550), Per/Per1/ Period Circadian Regulator 1 (OMIM: 602260) and Cry1/ Cryptochrome Circadian Regulator 1 (OMIM: 601933) were selected and analyzed (8). The primer lists were found in primer bank (http://pga.mgh.harvard. edu/cgi-bin/primerbank). The obtained cDNAs from all groups were used as template for RT-PCR. RTPCR conditions: $95^{\circ} \mathrm{C}^{\circ} 10^{\prime \prime}, 56^{\circ} 15^{\prime \prime}, 72^{\circ} \mathrm{C} 15^{\prime \prime}-45$ cycle (Roche Light Cycler 1.5). For internal control $\beta$-Actin gene was used [beta-actin housekeeping gene (5'-GTC CCT CAC CCT CCC AAA AG-3' (forward) and 5'-GCT GCC TCA ACA CCT CAA CCC-3' (reverse)]. Each RT-PCR reaction is performed in 20 $\mu \mathrm{l}(10 \mu \mathrm{l} 2 \mathrm{x}$ SYBR, $5 \mu \mathrm{l}$ c DNA, $0.5 \mu \mathrm{l}$ primer, $3 \mu \mathrm{l} \mathrm{d} \mathrm{H2O})$. Each sample was studied for three times for proper statistical results. Results were analyzed by "Roche Light Cycler1.5 software" (Table 1).

\section{Statistical Analyses}

Mean values and standard deviations were obtained, in cell viability assay. For evaluating the results of RT-PCR analyses, Student $T$ test was used in the comparison of groups. In these analyses, MS Excell was used. 
Table 1. The gene expression results of control and study groups.

\begin{tabular}{lccccccc}
\hline & Control & $\begin{array}{c}\mathbf{0 . 2 5} \mathbf{M m} \\
\text { Melatonin } \\
\text { Solution }\end{array}$ & P value & $\begin{array}{c}\mathbf{0 . 5} \mathbf{m M} \text { Melatonin } \\
\text { Solution }\end{array}$ & P value & $\begin{array}{c}\mathbf{1 . 0} \text { Mm Mela- } \\
\text { tonin Solution }\end{array}$ & $\begin{array}{c}\text { P value } \\
\text { Clock }\end{array}$ \\
\hline Bmal1/ ARNTL & $0.005 \pm 0.01$ & $0.007 \pm 0.01$ & $\geq 0.05$ & $0.022 \pm 0.01$ & $<0.05$ & $0.023 \pm 0.01$ & $<0.05$ \\
\hline Per1 & $0.015 \pm 0.01$ & $0.025 \pm 0.01$ & $\geq 0.05$ & $0.112 \pm 0.02$ & $<0.05$ & $0.092 \pm 0.03$ & $<0.05$ \\
\hline Cry1 & $0.121 \pm 0.01$ & $0.123 \pm 0.02$ & $\geq 0.05$ & $0.121 \pm 0.02$ & $\geq 0.05$ & $0.130 \pm 0.01$ & $\geq 0.05$ \\
\hline
\end{tabular}

\section{Results}

In our experiment, LD50 value of melatonin was found as $1.2 \pm 0.1 \mathrm{mM}$ in human neuroblastoma cells [SH-SY5Y-ATCC 8 CRL-2266 ${ }^{\mathrm{TM}}$ ] by using MTT cell proliferation assay (Figure 1).

In our study, we used $0.25 \mathrm{mM}, 0.50 \mathrm{mM}$ and $1.0 \mathrm{mM}$ melatonin concentrations. The concentrations which are close to LD50 were accepted as "high melatonin concentration group" (0.50 $\mathrm{mM}$ and $1.0 \mathrm{mM})$. The lowest melatonin concentration (0.25 mM) was accepted as "low melatonin concentration group" in our experiment.

Cell viability assay results were found as $80 \pm 0.9 \%$ in 0.25 $\mathrm{mM}, 73 \pm 1.2 \%$ in $0.5 \mathrm{mM}$ and $73 \pm 1.1 \%$ in $1.0 \mathrm{mM}$ melatonin solution applied groups. In control group, $81 \pm 1.2 \%$ was observed as cell viability ratio. In high melatonin concentration group, the cell viability ratio results were found statistically significant $(p<0.05)$. In low concentration group, the cell viability ratio was found statistically insignificant $(p \geq 0.05)$. (Figure 2$)$.

Gene expression results were found as approximately three and four times increased in Clock and Bmal1/ARNTL1 genes in high melatonin concentration group. The results were found statistically significant $(p<0.05)$. In Clock and Bmal1/ARNTL1 genes, no increase or decrease was found in low melatonin concentration group. This result was found statistically insignificant $(p \geq 0.05)$ (Table 1, Figure 3).

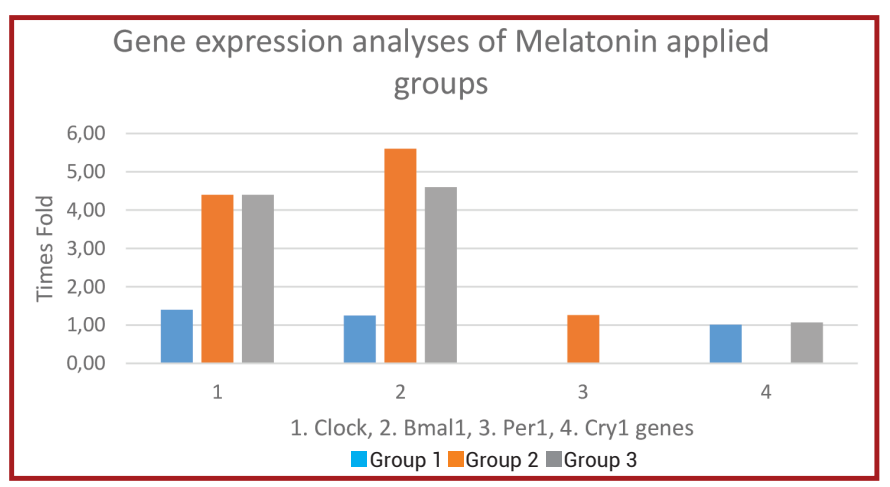

Figure 3. The graph represents gene expression analyses of Melatonin applied groups. Group 1 indicates $0.25 \mathrm{mM}$, group 2 indicates $0.50 \mathrm{mM}$, and group 3 indicates $1.00 \mathrm{mM}$ Melatonin solutions. (In Per1 gene, no expression difference was observed in $0.25 \mathrm{mM}$ and $1.00 \mathrm{mM}$ Melatonin solutions. In Cry1 gene, no expression difference was observed in $0.50 \mathrm{mM}$ Melatonin solutions.

In Per gene, no increase or decrease was found in all melatonin concentrations $(0.25 \mathrm{mM}, 0.5 \mathrm{mM}$ and $1 \mathrm{mM}$ melatonin solution). This result was found statistically insignificant $(p \geq 0.05)$ (Figure 2). In Cry1 gene, no increase or decrease was found in all melatonin concentrations. This result was found statistically insignificant $(p \geq 0.05)$ (Table 1, Figure 3 ).

\section{Discussion}

Melatonin is a hormone found naturally in the body. Melatonin is a hormone that regulates sleep-wake cycles. It is primarily released by the pineal gland. As a supplement, it is often used for the short-term treatment of trouble sleeping such as from jet lag or shift work (13). Circadian rhythms, endogenously generated in suprachiasmatic nuclei, seem to be under the direct influence of melatonin (14). Scientists work on the possible antidepressant effects of melatonin in these days (15). So, the effect of melatonin on neurons is still interesting. Here, melatonin's role on neuron cell viability was analyzed. Human neuroblastoma cell line was selected as a model. Cell-based assays are the main stay in drug discovery projects, where collections of compounds are screened to assess effects on cell viability, cell proliferation or show direct cytotoxic effects that eventually lead to cell death. Assessing cell viability is a key step in daily cell manipulation and often a requirement for subsequent processing and analysis (16). The trypan blue assay is used to determine the number of viable cells present in a cell suspension. It is based on the principle that live cells possess intact cell membranes that exclude certain dyes, whereas dead cells do not (17). In our study, high melatonin concentrations (0.50- $1.0 \mathrm{mM}$ melatonin concentrations) decreased neuroblastoma cell viability ratios. Despite of this, cell viability ratio was found as similar as in control group in low melatonin concentrations $(0.25 \mathrm{mM}$ melatonin concentration) (Figure 1). Previous studies have shown that melatonin also affects survival, proliferation, and apoptosis of the cells (18). It was demonstrated that melatonin application in neuronal cell culture cause anti-apopitotic affect. Melatonin's antioxidant effect probably causes neuroprotection of melatonin. It inhibits apopitosis in neurons (19-22). Our findings in low concentration group sported literature findings. In high concentrations of melatonin, neurotoxicity may be caused decrement ratio in neuron cell viability in our experiments (Figure 1).

Rhythmic variations in physiological and behavioral processes are mediated by both endogenous and exogenous factors. Clock genes and its' protein products are important in circadian rhythmic variations as endogenous factors (23). The expressions of Clock genes occur in all tissues, but especially in the suprachiasmatic nuclei of the hypothalamus, which regulate circadian rhythms in brain. Melatonin probably acts on the suprachiasmatic nuclei directly influencing the circadian Clock mechanisms $(24,25)$. Clock genes are associated with neurological functions and disorders. So, these genes may be potential targets for melatonin in a neuron cell (24-26). In new studies, it was found that melatonin effects on both fragile $X$ mental retardation protein (FMRP) and reactive oxygen species (ROS). Melatonin regulates the GABAergic signal system in neurons. FMRP protein is important in memory functions and its' expression reduces in neurodegenerative disorders. 
Reduced FMRP expression may result in synaptic dysfunction. Melatonin may prevent synaptic dysfunction through FMRP regulation (27). Here, we looked for the gene expressions of Clock genes in melatonin usages on neuroblastoma cells.

The protein encoded by Clock gene plays a central role in the regulation of circadian rhythms as a transcription factor. Clock as a protein belongs to a basic helix-loop-helix family and contains DNA binding histone acetyltransferase activity. It forms a heterodimer with Bmal1/ARNTL. Bmal1 protein encoded by this gene is a basic helix-loop-helix protein that forms a heterodimer with Clock protein. This huge molecule (Clock/ Bmal1) binds E-box enhancer elements upstream of Period (Per1, Per2, Per3) and Cryptochrome (Cry1, Cry2) genes and activates transcription of these genes. Per and Cry proteins heterodimerize and repress their own transcription by interacting in a feedback loop with Clock/ARNTL complexes $(26,28)$. In our experiments, melatonin increased the gene expressions of Clock and Bmal1 genes in high concentration group (Table 1, Figure 3). In low concentration group, no affect was observed in Clock and Bmal1 genes (Table 1, Figure 3).

These are the preliminary results which represents the role of melatonin in the transcription of these two genes on neuroblastoma cells. Guissoni Campos et al. explained recently that the highest expression of Per seen in the daytime analysis coincided with the highest expression of melatonin receptors in neuron and glia in primate cerebellum (29). Hiragaki et al. reported that melatonin signaling may be important for the regulation of clock gene expression in the inner or ganglion cells layer, but not in photoreceptors (30). Jilg et al. pointed out that melatonin shapes time-of-day-dependent learning efficiency in parallel to consolidating expression patterns of clock genes in the mouse hippocampus (31). These findings belong to "in vivo" studies on different animals including primates and mice. The findings observed in our experiments belong to "in vitro" studies. The increment values in Clock and Bmal1 gene expressions on neurons support the literature findings. So, the relationship between melatonin and Clock genes seems important for further studies.

\section{Acknowledgments}

Study was designed by VT, MZB, and SG. Data was collected and analyzed by DZC, VT, MZB, YEP, YCK, ZZK, OK. Manuscript was written by VT and ŞG. There was no financial assistance with the project.

\section{Conflict of Interest}

The authors declared they do not have anything to disclose regarding conflict of interest with respect to this manuscript.

\section{References}

1. Amaral FGD, Cipolla-Neto J. A brief review about melatonin, a pineal hormone. Arch Endocrinol Metab. 2018;62(4):472-479.

2. von Gall C, Weaver DR, Moek J, Jilg A, Stehle JH, Korf HW. Melatonin plays a crucial role in the regulation of rhythmic clock gene expression in the mouse pars tuberalis. Ann N Y Acad Sci. 2005;1040(4):508-511.

3. Tamtaji OR, Mirhosseini N, Reiter RJ, Azami A, Asemi Z. Melatonin, a calpain inhibitor in the central nervous system: Current status and future perspectives. J Cell Physiol. 2019;234(2):1001-1007.
4. Schuch JB, Genro JP, Bastos CR, Ghisleni G, Tovo-Rodrigues $\mathrm{L}$. The role of CLOCK gene in psychiatric disorders: Evidence from human and animal research. Am J Med Genet B Neuropsychiatr Genet. 2018;177(2):181198.

5. Gagnon K, Godbout R. Melatonin and comorbidities in children with autism spectrum disorder. Curr Dev Disord Rep. 2018;5(3):197-206.

6. Uzuner SC. Development of a Direct Trypan Blue Exclusion Method to Detect Cell Viability of Adherent Cells into ELISA Plates. Celal Bayar University Journal of Science 2018;4(1):99-104.

7. Köhler A, Hurt E. Exporting RNA from the nucleus to the cytoplasm. Nature Reviews. Molecular Cell Biology 2007;8(10):761-773.

8. Freeman WM, Walker SJ, Vrana KE. Quantitative RT-PCR: pitfalls and potential. BioTechniques 1999;26(1):112-122.

9. Çoban ZD, Kayır H, Güran Ş. Sorefenib inhibits the expressions of heat shock protein70 gene on multiple myeloma (RPMI-8226) and plasma cell leukemia (ARH-77) cell lines. Gulhane Med J. 2017;59(1):6-10.

10. Jahn K, Wieltsch $\mathrm{C}$, Blumer $\mathrm{N}$, et al. A cell culture model for investigation of synapse influenceability: epigenetics, expression and function of gene targets important for synapse formation and preservation in SH-SY5Y neuroblastoma cells differentiated by retinoic acid. J Neural Transm (Vienna). 2017;124(11):1341-1367.

11. Güran Ş, Çoban ZD, Karasimav Ö, et al. Dextrose solution used for prolotherapy decreases cell viability and increases gene expressions of angiogenic and apopitotic factors. Gulhane Med J. 2018;60(2):42-46.

12. Coco-Martin JM, Oberink JW, van der Velden-de Groot TA, Beuvery EC. Viability measurements of hybridoma cells in suspension cultures. Cytotechnology 1992;8(1):57-64.

13. Auld F, Maschauer EL, Morrison I, Skene DJ, Riha RL. Evidence for the efficacy of melatonin in the treatment of primary adult sleep disorders. Sleep Med Rev. 2017;34: 10-22.

14. Stehle J, Vanecek J, Vollrath L. Effects of melatonin on spontaneous electrical activity of neurons in rat suprachiasmatic nuclei: an in vitro iontophoretic study. Journal of Neural Transmission 1989;78(2):173-177.

15. Valdés-Tovar M, Estrada-Reyes R, Solís-Chagoyán $H$, et al. Circadian modulation of neuroplasticity by melatonin: a target in the treatment of depression. British Journal of Pharmacology 2018;175 (16): 3200-3208.

16. Çoban ZD, Avcu F, Ural AU, Akyol M, Güran Ş. Cytotoxic effect of docetaxel on multiple myeloma cell lines (RPMI- 8226) as a chemotherapotic agent. Gulhane Med J. 2011;53(4):258-263.

17. Mascotti K, McCullough J, Burger SR. HPC viability measurement: trypan blue versus acridine orange and propidium iodide.Transfusion. 2000;40(6):693-696.

18. Kocak N, Donmez H, Yildirim IH. Effects of melatonin 
on apoptosis and cell differentiation in MCF-7 derived cancer stem cells. Cell Mol Biol (Noisy-le-grand). 2018;64(12):56-61.

19. Chen ST, Chuang JI. The antioxidant melatonin reduces cortical neuronal death after intrastriatal injection of kainate in the rat. Exp Brain Res. 1999;124(2):241-247.

20. Kim YS, Joo WS, Jin BK, Cho YH, Baik HH, Park CW. Melatonin protects 6-OHDA-induced neuronal death of nigrostriatal dopaminergic system. Neuroreport. 1998;9(10):2387-2390.

21. Sirichoat A, Krutsri S, Suwannakot K, et al. Melatonin protects against methotrexate-induced memory deficit and hippocampal neurogenesis impairment in a rat model. Biochem Pharmacol. 2019;163:225-233.

22. He R, Cui M, Lin H, Zhao L, Wang J, Chen S, Shao Z. Melatonin resists oxidative stress-induced apoptosis in nucleus pulposus cells. Life Sci. 2018;199(4):122-130.

23. Piggins HD. Human clock genes. Ann Med. 2002;34(5):394-400.

24. Wang Y, Zeng S. Melatonin Promotes Ubiquitination of Phosphorylated Pro-Apoptotic Protein Bcl-2-Interacting Mediator of Cell Death-Extra Long (BimEL) in Porcine Granulosa Cells. Int J Mol Sci. 2018;19(11):140-149.

25. Vriend J, Reiter RJ. Melatonin feedback on clock genes: a theory involving the proteasome. J Pineal Res. 2015;58(1):1-11.

26. Hardin PE. Essential and expendable features of the circadian timekeeping mechanism. Curr Opin Neurobiol. 2006;16(6):686-692.

27. Kwon KJ, Lee EJ, Kim MK, et al. The potential role of melatonin on sleep deprivation-induced cognitive impairments: implication of FMRP on cognitive function. Neuroscience 2015;301(4):403-414.

28. $\mathrm{Yu}$ W, Zheng $\mathrm{H}$, Houl JH, Dauwalder B, Hardin PE. PER-dependent rhythms in CLK phosphorylation and E-box binding regulate circadian transcription. Genes Dev. 2006;20(6):723-733.

29. Guissoni Campos LM, Hataka A, Vieira IZ, et al. Circadian Clock Proteins and Melatonin Receptors in Neurons and Glia of the Sapajus apella Cerebellum. Front Physiol. 2018;9:5.

30. Hiragaki S, Baba K, Coulson E, Kunst S, Spessert R, Tosini G. Melatonin signaling modulates clock genes expression in the mouse retina. PLoS One. 2014;9(9):106109.

31. Jilg A, Bechstein P, Saade A, et al. Melatonin modulates daytime-dependent synaptic plasticity and learning efficiency. J Pineal Res. 2019;66(3):e12553. 